\title{
Preoperative and Postoperative Gleason Score Correlation of Patients Who Underwent Radical Prostatectomy
}

\author{
(1) Ekrem Güner, (1) Abdulmuttalip Şimşek \\ Bakırköy Dr. Sadi Konuk Training and Research Hospital, Clinic of Urology, Istanbul, Turkey
}

\begin{abstract}
Objective: We aimed to report the consistency between transrectal needle biopsy (TRNB) Gleason scores (GSs) and prostatectomy specimen GSs based on upgrading and downgrading rates.

Materials and Methods: Data of patients who underwent open, laparoscopic or robot-assisted radical prostatectomy with the diagnosis of prostate cancer between 2006 and 2018 were retrospectively reviewed.

Results: Two hundred and fifty two patients were included in the study. The mean age of the patients was $61.9 \pm 6.1$ years. The mean serum prostatespecific antigen (PSA) TRNB was $9 \pm 5.3 \mathrm{ng} / \mathrm{dL}$. The distribution of TRNB GSs was as follows: $\mathrm{G} 6(3+3)=178, \mathrm{G} 7(3+4)=21, \mathrm{G} 7(4+3)=48, \mathrm{G} 8(4+4)=1$, $\mathrm{G} 9(4+5)=9$. According to the final pathology result after radical prostatectomy, GSs were as follows: $G 6(3+3)=141, G 7(3+4)=25, G 7(4+3)=74, G 8$ $(4+4)=3, G 9(4+5)=8$. Prostate cancer was limited to prostate in 220 patients and extracapsular spread was observed in 32 patients. There was seminal vesicle invasion in 24 patients and perineural invasion in 49 patients. When TRNB GSs and prostatectomy specimen GSs were compared, 57 (22.6\%) patients were upgraded and nine (3.6\%) patients had downgrading. The preoperative PSA of the patients undergoing upgrading were significantly higher than those without upgrading, $10.7+6.2 \mathrm{ng} / \mathrm{dL}$ versus $8.5+4.9 \mathrm{ng} / \mathrm{dL}, \mathrm{p}=0.018$. The age and body mass index of the upgrading and nonupgraded patients were similar, $p=0.598$ and $p=0.133$, respectively.

Conclusion: Upgrading in the final pathology assessment after radical prostatectomy is still an important problem for clinicians today. It may be beneficial to develop biopsy sampling techniques for accurate grading of the disease and to use radiological imaging for this purpose.

Keywords: Prostate cancer, prostate specific antigen, pathology, upgrade, downgrade
\end{abstract}

\section{Introduction}

Prostate cancer remains the most common form of cancer in men in the United States in 2018. It is also the second most common cause of cancer-related death (1). In the diagnosis of prostate cancer, digital rectal examination, serum prostate-specific antigen (PSA), and transrectal or transperineal ultrasound-guided prostate biopsy are used (2). Gleason scoring system plays a vital role in the management of prostate cancer. Gleason scoring is expressed as the sum of the primary and highest/worst grade score in samples from different anatomical regions. Conflicts between prostate biopsy and radical prostatectomy specimens remain a critical problem in clinical practice. Especially after the 2005 International Society of Urologic Pathology (ISUP) consensus, some researchers reported that the Gleason Score (GS) consistency of transrectal needle biopsy (TRNB) and biopsy and 'prostatectomy specimen pathology' increased increased. Studies conducted between 2005 and 2014 showed that the upgrading rate ranged from $22 \%$ to $47 \%$, and the downgrading rate ranged from $5 \%$ to $21 \%(3)$.

In this study, we aimed to report the consistency between TRNB GSs and prostatectomy specimen GSs the upgrading and downgrading rates.

\section{Materials and Methods}

After the approval of our study with the decision of the local ethics committee of our hospital (2019-271), the data of patients who underwent open, laparoscopic or robot-

Cite this article as: Güner E, Şimşek A. Preoperative and Postoperative Gleason Score Correlation of Patients Who Underwent Radical Prostatectomy Bull Urooncol 2020;19(1):35-37

Address for Correspondence: Ekrem Güner, Bakırköy Dr.Sadi Konuk Training and Research Hospital, Clinic of Urology, İstanbul, Turkey E-mail: ekremguner@yahoo.com ORCID-ID: orcid.org/0000-0002-4770-7535 Received: 05.08.2019 Accepted: 08.08.2019 
assisted radical prostatectomy with the diagnosis of prostate cancer between 2006-2018 were retrospectively reviewed. The parameters analyzed included demographic data, preoperative and postoperative PSA values, TRNB and prostatectomy specimen results. All male patients aged between 40 and 75 were included in the study. Patients with malignancy other than prostate adenocarcinoma, and patients who received radiotherapy, hormonotherapy, or chemotherapy before prostatectomy were excluded from the study.

Transrectal ultrasound-guided prostate biopsy was performed by urologists experienced in the transrectal biopsy. A biopsy was taken from 12 prostate cores.

\section{Statistical Analysis}

In the statistical analysis of the data, IBM SPSS (Statistical Package for Social Sciences) was used. Continuous variables were given as mean \pm standard deviation, while categorical variables were given as numbers and percentages. The normality of the data was evaluated with the Kolmogorov-Smirnov test. Student's t-test and Mann-Whitney $U$ test were used to compare the continuous variables of the two groups, and the chi-square test was used to evaluate the categorical data. $\mathrm{P}<0.05$ was considered statistically significant.

\section{Results}

In total, 252 patients were included in the study. The mean age of the patients was $61.9 \pm 6.1$ years. The mean PSA before TRNB was $9 \pm 5.3 \mathrm{ng} / \mathrm{dL}$. The mean body mass index (BMI) of the patients was $27 \pm 1.4 \mathrm{~kg} / \mathrm{m}^{2}$. The distribution of TRNB GSs was as follows: G6 $(3+3)=178, \mathrm{G} 7(3+4)=21, \mathrm{G} 7(4+3)=48$, G8 $(4+4)=1$, G9 $(4+5)=9$. According to the final pathology result after radical prostatectomy, GSs were as follows: G6 $(3+3)=141$, G7 $(3+4)=25$, G7 $(4+3)=74$, G8 $(4+4)=3$, G9 $(4+5)=8$ (Table 1$)$. While prostate cancer was limited to prostate in 220 patients, extracapsular extension was observed in 32 patients. There was invasion in seminal vesicles in 24 patients and perineural invasion in 49 patients. Comparing TRNB GS and final pathology yerine prostatectomy specimen GS, 57 patients $(22.6 \%)$ had upgrading and nine patients (3.6\%) had downgrading. Preoperative PSA of the patients with upgrading were significantly higher than those without upgrading $(10.7+6.2 \mathrm{ng} / \mathrm{dL}$ vs $8.5+4.9 \mathrm{ng} / \mathrm{dL}, \mathrm{p}=0.018)$. The age and $\mathrm{BMI}$ of the patients with and without upgrading were similar ( $\mathrm{p}=0.598$ and $\mathrm{p}=0.133$, respectively) (Table 2 ).

\section{Discussion}

Prostate needle biopsy is the gold-standard method in the diagnosis of prostate cancer and is one of the most common procedures in daily urology practice. It is reported that at least 800,000 prostate biopsies are performed annually in the United States (2).

The correct determination of the GS is vital for the treatment and prognostic management of the disease. In the consensus meeting held by ISUP 2005, Gleason scoring was updated to ensure that biopsy evaluations are more reliable (4).
In a study conducted by Corcoran et al. (5) in 1629 prostate cancer patients, GSs were compared in TRNB and prostatectomy pathologies, and upgrading was observed in radical prostatectomy Gleason score in 466 patients (28.6\%). In multivariate analysis, GS upgrading was evaluated as a marker for biochemical recurrence after radical prostatectomy. In our current study, upgrading was observed similarly with a rate of $22.6 \%$.

In their study, which included 286 patients undergoing robotassisted radical prostatectomy, Henderickx et al. (6) divided patients into risk groups and reported $58.7 \%$ upgrading in the low-risk group, 30.2\% upgrading in the middle-risk group, and $25 \%$ upgrading in the high-risk group. The authors emphasized that the GS was estimated lower in the pre-operative period. In a study conducted by D'Elia et al. (2) with 300 patients, the most common TRNB pathology was reported to be G6 $(3+3)$ with $64 \%$, while upgrading was observed in approximately $39.7 \%$ of patients. As a result of multivariate analysis, it was found that only PSA less than $4 \mathrm{ng} / \mathrm{mL}$ predicted upstaging. In our study, G6 $(3+3)$ was the most common prostatectomy pathology, with a rate of $56 \%$. However, in our current study, PSA of patients with upgrading were significantly higher than those without upgrading.

\begin{tabular}{|l|l|}
\hline \multicolumn{2}{|l|}{ Table 1. Demographic and clinical features of the patients } \\
\hline Variable & Value \\
\hline Age (year) & $61.9 \pm 6.1$ \\
\hline BMI $\left(\mathrm{kg} / \mathrm{m}^{2}\right)$ & $27 \pm 1.4$ \\
\hline Preoperative PSA & $9 \pm 5.3$ \\
\hline TRNB Gleason score & $178(70.6 \%)$ \\
\hline $3+3$ & $21(8.3 \%)$ \\
\hline $3+4$ & $48(19 \%)$ \\
\hline $4+3$ & $1(0.4 \%)$ \\
\hline $4+4$ & $4(1.6 \%)$ \\
\hline $4+5$ & \multicolumn{2}{|l}{} \\
\hline Prostatectomy Specimen Gleason score & $141(56 \%)$ \\
\hline $3+3$ & $25(9.9 \%)$ \\
\hline $3+4$ & $74(29.4 \%)$ \\
\hline $4+3$ & $3(1.2 \%)$ \\
\hline $4+4$ & $8(3.2 \%)$ \\
\hline $4+5$ & $1(0.4 \%)$ \\
\hline $5+5$ & \multicolumn{2}{|l}{} \\
\hline $\begin{array}{l}\text { BMl: Body mass index, PSA: Prostate specific antigen, TRNB: Transrectal needle } \\
\text { biopsy }\end{array}$ & \\
\hline
\end{tabular}

Table 2. Comparison of the patients according to changing pathological grade

\begin{tabular}{|l|l|l|l|}
\hline Variables & $\begin{array}{l}\text { Pathological } \\
\text { upgraded group } \\
(\mathbf{n}=57)\end{array}$ & $\begin{array}{l}\text { Pathological } \\
\text { non-upgraded } \\
\text { group } \\
(\mathbf{n}=\mathbf{1 8 6})\end{array}$ & $\mathbf{p}$ \\
\hline Age (year) & $62.2 \pm 6.2$ & $61.7 \pm 6.1$ & 0.598 \\
\hline BMI $\left(\mathrm{kg} / \mathrm{m}^{2}\right)$ & $26.7 \pm 1.5$ & $27.1 \pm 1.3$ & 0.133 \\
\hline Preoperative PSA & $10.7 \pm 6.2$ & $8.5 \pm 4.9$ & 0.018 \\
\hline BMI: Body mass index, PSA: Prostate specific antigen \\
\hline
\end{tabular}


In a study by de Cobelli et al. (7) in which 311 patients who were appropriate for active surveillance and who underwent radical prostatectomy, the BMI was found to be significantly associated with upgrading, upstaging, and seminal vesicle invasion.

When the data of 10,273 patients with prostatectomy and low-risk prostate cancer recorded in the the Surveillance, Epidemiology, and Ends Results database were evaluated, it was observed that $44 \%$ of the patients had upgrading and $9.7 \%$ of them had upstaging after radical prostatectomy. In this study, the age, PSA, and positive biopsy core percentage were associated with upgrading and upstaging (8). Similarly, in our current study, PSA of patients who had upgrading were found to be significantly higher than those without upgrading. However, there was no difference in age.

In another study conducted by Maurice et al. (9), the rate of upgrading on GS 6 after radical prostatectomy was $43.3 \%$ in the disease localized to the prostate, while the rates of upgrading and upstaging of African Americans were higher than other races. Our current study was conducted in the Turkish population, and the rate of upgrading (22.6\%) was significantly lower than the study mentioned.

Park et al. (10) evaluated whether patients with Gleason 7 $(3+4)$ prostate cancer in prostate biopsy could be candidates for active surveillance. In this study, the overall upgrading rate was found to be $31.8 \%$. While the pre-operative PSA were significantly higher in patients with upgrading, the optimal threshold PSA for predicting upgrading was $4.73 \mathrm{ng} / \mathrm{mL}(85.7 \%$ sensitivity, $57.8 \%$ specificity).

Some methods have been proposed to predict pathological upgrading after prostate biopsy and subsequent radical prostatectomy. Some of these are PSA density (11) and exome genotyping (12). In a study by Oh et al. (12), Rs33999879 single nucleotide polymorphism was shown to be associated with GS pathological upgrading (12). Since our current study is a retrospective study, these data could not be shared. However, they can be useful to guide future studies.

\section{Conclusions}

Upgrading in final pathology evaluation after radical prostatectomy is still an essential problem for clinicians today. It may be beneficial to develop biopsy sampling techniques for the correct grading of the disease and to use radiological imaging for this.

\section{Acknowledgements}

Publication: The results of the study were not published in full or in part in form of abstracts.

Contribution: There is not any contributors who may not be listed as authors.

Conflict of Interest: No conflict of interest was declared by the authors.

Financial Disclosure: The authors declared that this study received no financial support.

\section{Ethics}

Ethics Committee Approval: Ethical approval was obtained from Bakırköy Dr. Sadi Konuk Training and Research Hospital Ethics Committee (no: 2019/271).

Informed Consent: Retrospective study.

Peer-review: Externally peer-reviewed.

\section{Authorship Contributions}

Concept: E.G., Design: E.G., Data Collection or Processing: E.G., Analysis or Interpretation: E.G., Literature Search: E.G., Writing: E.G., A.Ş.

\section{References}

1. Bekelman JE, Rumble RB, Freedland SJ. Clinically Localized Prostate Cancer: ASCO Clinical Practice Guideline Endorsement of an AUA/ ASTRO/SUO Guideline Summary. J Oncol Pract 2018;14:618-624.

2. D'Elia C, Cerruto MA, Cioffi A, Novella G, Cavalleri S, Artibani W. Upgrading and upstaging in prostate cancer: From prostate biopsy to radical prostatectomy. Mol Clin Oncol 2014;2:1145-1149.

3. Athanazio D, Gotto G, Shea-Budgell M, Yilmaz A, Trpkov K. Global Gleason grade groups in prostate cancer: concordance of biopsy and radical prostatectomy grades and predictors of upgrade and downgrade. Histopathology 2017;70:1098-1106.

4. Epstein Jl, Allsbrook WC Jr, Amin MB, Egevad LL; ISUP Grading Committee. The 2005 International Society of Urological Pathology (ISUP) Consensus Conference on Gleason Grading of Prostatic Carcinoma. Am J Surg Pathol 2005;29:1228-1242.

5. Corcoran NM, Hong MK, Casey RG, et al. Upgrade in Gleason score between prostate biopsies and pathology following radical prostatectomy significantly impacts upon the risk of biochemical recurrence. BJU Int 2011;108:E202-210.

6. Henderickx MMEL, Brits $T$, Muilwijk T, Adams T, Vandeursen $H$. Localized prostate cancer and robot-assisted laparoscopic radical prostatectomy: a retrospective, comparative study between pre- and post-operative Gleason scores. Acta Chir Belg 2018;118:15-20.

7. de Cobelli O, Terracciano D, Tagliabue E, et al. Body mass index was associated with upstaging and upgrading in patients with low-risk prostate cancer who met the inclusion criteria for active surveillance. Urol Oncol 2015;33:201.e1-8.

8. Dinh KT, Mahal BA, Ziehr DR, et al. Incidence and Predictors of Upgrading and Up Staging among 10,000 Contemporary Patients with Low Risk Prostate Cancer. J Urol 2015;194:343-349.

9. Maurice MJ, Sundi D, Schaeffer EM, Abouassaly R. Risk of Pathological Upgrading and Up Staging among Men with Low Risk Prostate Cancer Varies by Race: Results from the National Cancer Database. J Urol 2017; 197:627-631.

10. Park HJ, Ha YS, Park SY, et al. Incidence of upgrading and upstaging in patients with low-volume Gleason score $3+4$ prostate cancers at biopsy: finding a new group eligible for active surveillance. Urol Int 2013;90:301-305.

11. Sfoungaristos $S$, Katafigiotis I, Perimenis P. The role of PSA density to predict a pathological tumour upgrade between needle biopsy and radical prostatectomy for low risk clinical prostate cancer in the modified Gleason system era. Can Urol Assoc J 2013;7:E722-27.

12. Oh JJ, Park S, Lee SE, et al. The use of exome genotyping to predict pathological Gleason score upgrade after radical prostatectomy in low-risk prostate cancer patients. PLoS One 2014;9:e104146. 